\title{
Modulatory Synaptic Actions of an Identified Histaminergic Neuron on the Serotonergic Metacerebral Cell of Aplysia
}

\author{
Klaudiusz R. Weiss, ${ }^{\star}$ Eli Shapiro, and Irving Kupfermann† \\ Center for Neurobiology \& Behavior, The New York State Psychiatric Institute, New York, New York 10032, \\ Departments of †Physiology, ${ }^{*}$ Anatomy and Cell Biology, and *†Psychiatry, ${ }^{*}$ †Columbia University College of \\ Physicians and Surgeons, and *School of Dental and Oral Surgery, New York, New York 10032
}

Possible sources of excitatory synaptic input to the serotonergic metacerebral cell (MCC) were determined by stimulating various neurons in the cerebral ganglion. Firing of the previously identified histaminergic neuron $\mathrm{C} 2$ was found to produce synaptic input to the MCC. The synaptic input consists of fast excitatory-inhibitory synaptic potentials on a background of a slow EPSP. The slow EPSP appears to be monosynaptic and chemically mediated since (1) it persists in a solution of high divalent cations; (2) broadening of the presynaptic spike enhances the EPSP; (3) the size of the EPSP is a function of the $\mathrm{Mg}^{2+}$ and $\mathrm{Ca}^{2+}$ concentrations of the bathing solution; and (4) the EPSP can be mimicked by application of histamine to the MCC. The slow EPSP, in addition to firing the MCC, can increase the excitability of the cell, even under conditions in which C2 is fired at a rate too slow to produce a measurable EPSP when the MCC is at rest potential. This property appears to be due to the fact that the slow EPSP results from an apparent decrease of membrane conductance so that the size of the EPSP increases markedly as the cell is depolarized, and the EPSP appears to be highly voltage-dependent so that it is small or absent close to the rest potential of the MCC. When the MCC is voltage-clamped, application of histamine to the bath results in an inward current that disappears when the MCC is hyperpolarized. The potential at which the histamine-induced current reverses or disappears is dependent on the concentration of external potassium, suggesting that, at least in part, the slow EPSP is due to a decrease of potassium conductance. The data on C2 are consistent with its being an element of the neuronal system that mediates a state of food arousal in Aplysia.

In the study of the neural basis of behavior, a major question of theoretical as well as clinical interest is, What are the mechanisms that modulate overall behavioral responsiveness? What factors determine global modulatory phenomena such as sleepwakefulness, arousal-dearousal and alteration of mood? Feeding behavior in Aplysia provides a convenient and tractable model system for the study of a variety of modulatory variables. One such variable we have studied is food arousal, a behavioral state that is elicited by briefly exposing animals to food stimuli (Weiss and Kupfermann, 1977). The food arousal state in Aplysia is reflected by specific alterations of feeding behavior (Kupfermann, 1974; Susswein et al., 1978), as well as by generalized changes in behavior such as locomotion (Kupfermann, 1974)

\footnotetext{
Received Oct. 22, 1985; revised Feb. 18, 1986; accepted Feb. 20, 1986.

We wish to thank Drs. T. J. Carew, V. F. Castellucci, E. R. Kandel, and J. Koester for their comments and discussions. This work was supported in part by PHS Grants MH35564, GM320099, and RSDA MH00304

Correspondence should be addressed to Dr. I. Kupfermann, Center for Neurobiology \& Behavior, 722 West 168th Street, Psychiatric Institute Annex-8th floor, New York, NY 10032

Copyright (C) 1986 Society for Neuroscience $0270-6474 / 86 / 082393-10 \$ 02.00 / 0$
}

and cardiovascular responses (Dieringer et al., 1978; Koch et al., 1984). Several serotonergic neurons have been shown to mediate different behavioral manifestations of the food arousal state. Considerable evidence (Kupfermann and Weiss, 1982; Rosen et al., 1983; Weiss et al., 1975, 1978a, 1979) indicates that alterations of both the speed and intensity of biting are mediated by the metacerebral cell (MCC; also sometimes referred to as $\mathrm{Cl}$ or GCN), a giant serotonergic neuron (Eisenstadt et al., 1973; Gerschenfeld and Paupardin-Tritsch, 1974; Gerschenfeld et al., 1978; Weinreich et al., 1973) located in the cerebral ganglion. The metacerebral cell is normally inactive, but is prompted into activity by food stimuli (Kupfermann and Weiss, 1982; Weiss el al., 1986a). Tactile stimuli and other sensory in puts that elicit the food arousal state also can excite the MCC. We have hypothesized (Kupfermann and Weiss, 1981; Weiss et al., 1982) that food and other stimuli may activate a "central arousal system" consisting of a group of interrelated neurons that provide the excitatory drive to various subsets of neurons that then execute the appropriate effects of the arousal state on different classes of behavior. The MCC specifically mediates arousal effects on the buccal musculature (Weiss et al., $1975,1978 \mathrm{a})$. Three observations support the hypothesis of a central arousal system: (1) Food arousal is associaled with a set of coordinated changes in multiple effector systems; (2) spike activity of the MCC outlasts the initiating stimulus; and (3) spike activity can be reinitiated much more readily for a long period after the cell is first excited by a brief arousing stimulus.

In order to explore a possible central arousal system we have attempted to define neurons that excite the MCC. In a previous study, Rosen et al. (1982) identified a population of mechanosensory neurons that provide one source of excitatory input to the MCC. This input, however, is weak, rapidly decrements, and does not outlast the food stimulus. We therefore sought other neurons that provide excitatory drive to the MCC. In this paper we report that the previously identified histaminergic neuron, C2 (McCaman and McKenna, 1978; McCaman and Weinreich, 1982, 1985; Weinreich 1977, 1978; Weinreich and $\mathrm{Yu}$, 1977; Weinreich el al., 1975), produces a relatively large, nondecrementing excitatory synaptic input to the MCC. In accompanying papers (Chiel et al., 1986; Weiss et al., 1986a, b), we describe evidence that the histamine cell is a proprioceptive afferent neuron that is active during feeding behavior and that, in addition to its excitatory effect on the MCC, it has multiple actions on neurons involved in the coordination and patterning of feeding behavior. We conclude that $\mathrm{C} 2$ has some of the features expected of an element of a central arousal system, but other features indicate that it is a unique modulatory sensory neuron that does not readily fit into existing functional categories.

Some of the results presented in this paper have appeared in a preliminary communication (Weiss et al., 1978b). 


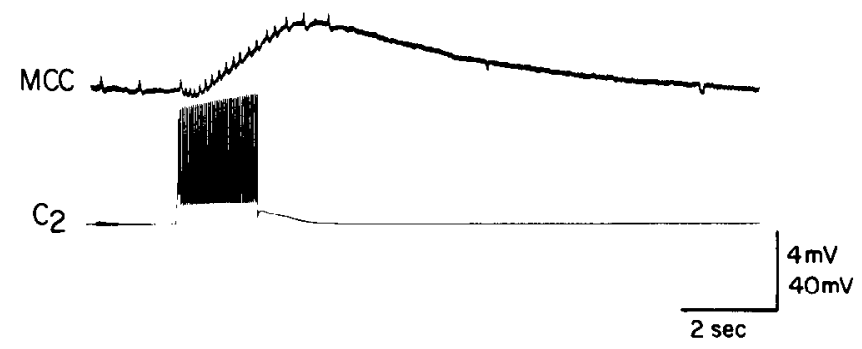

Figure 1. Response of the MCC to activation of the histaminergic neuron $\mathrm{C} 2$. Activation of cell $\mathrm{C} 2$ produces a series of fast potentials (excitatory-inhibitory) and a slow depolarization of long duration.

\section{Materials and Methods}

Experiments were performed on Aplysia californica weighing 100-250 gm, supplied by Pacitic Bio-Marine Co. (Venice, CA). They were maintained in 500 liter tanks containing aerated artificial seawater (ASW; Instant Ocean) at $15^{\circ} \mathrm{C}$. For dissection, the animals were anesthetized by the injection of isotonic magnesium chloride $(25 \% \mathrm{vol} / \mathrm{wt})$. Isolated cerebral ganglia were then pinned, dorsal side up, to the Sylgard base of a $5 \mathrm{ml}$ chamber. Connective tissue was dissected, while the ganglia were bathed in a solution of ASW containing $4 \times$ the normal content of $\mathrm{Mg}^{2+}$ and $0.5 \times$ the normal content of $\mathrm{Ca}^{2+}$. In order to reduce possible contractions of the ganglionic sheath when transmitters were to be bathapplied, the ganglion was immersed for $45 \mathrm{sec}$, prior to desheathing, in a solution of ASW containing $0.5 \%$ glutaraldehyde. Experiments were performed at room temperature.

For intracellular stimulation and recording, neurons were impaled with double-barreled microelectrodes filled with $2 \mathrm{~m}$ potassium citrate and beveled with $0.05 \mu \mathrm{m}$ grit (K. T. Brown type beveler). In experiments requiring accurate measurements of membrane potential, in addition to being impaled with a double-barreled electrode, the cells were impaled with a single-barrel electrode that was used to pass current. All preamplifiers were equipped with bridge circuits to nullify coupling potentials. The signals were led from the preamplifiers to an oscilloscope, an FM tape recorder, and a Gould pen-writer from which the hard copy of the data was obtained.

In voltage-clamp experiments, the voltage and current electrodes were filled, respectively, with $2 \mathrm{~m}$ potassium chloride and $2 \mathrm{M}$ potassium acetate. The resistance of these electrodes varied from 2 to $4 \mathrm{M} \Omega$. In order to reduce artifacts and oscillations, electrodes were shielded with aluminum foil wrapped around parafilm, which covered the electrodes. A Dagan voltage-clamp model 2500 preamplifier was used in these experiments. Unless otherwise noted, all experiments were repeated at least $3 \times$.

\section{Results}

\section{Histaminergic neuron $C 2$ excites the metacerebral cell}

Exploration of the cerebral ganglion revealed that the left and right E clusters (Jahan-Parwar and Fredman, 1976) each contain a characteristic neuron that, when fired by intracellular stimulation, consistently produces excitatory synaptic input to the MCC. The position, appearance, and size of this neuron suggested (Weiss et al., 1978b) that it was the previously identified histaminergic neuron, C2 (McCaman and McKenna, 1978; McCaman and Weinreich, 1982; Weinreich, 1977, 1978; Weinreich and Yu, 1977; Weinreich et al., 1975). Although previous studies of $\mathrm{C} 2$ did not reveal that it made synaptic connections with the MCC, D. Weinreich (personal communication) and then Ono and McCaman (1980) confirmed our findings (Weiss et al., 1978b) that this connection was present. Consistent with the conclusion that the neuron was $\mathrm{C} 2$, we found that, as previously and subsequently reported (McCaman and McKenna, 1978; McCaman and Weinreich, 1982; Ono and McCaman, 1980; Weinreich, 1977), this cell made extensive synaptic connections with other cells in the E cluster. Furthermore, although the MCC showed only weak responses to histamine applied directly to its cell body, the application of histamine to the bath consistently produced a slow depolarization that had properties similar to the slow depolarization produced by the firing of $\mathrm{C} 2$ (Weiss et al., 1978b).

The synaptic potential evoked by $\mathrm{C} 2$ in the $\mathrm{MCC}$ is very slow in onset (Fig. 1) and is generally not seen unless a train of action potentials in $\mathrm{C} 2$ is elicited. The rising phase of the slow depolarization often exhibited small potentials that had the appearance of the joint excitatory-inhibitory potentials that occur spontaneously in the MCC(Weiss and Kupfermann, 1976). While the slow depolarization was consistently evoked in the same preparation, as well as between preparations, the fast potentials were not always seen, and when evoked they did not follow onefor-one the spikes in $\mathrm{C} 2$. We conducted a series of experiments to test the monosynapticity and the chemical nature of the synaptic potential evoked in the MCC by cell $\mathrm{C} 2$. Figure $2 A$ shows that the synaptic potentials were blocked in a solution containing increased $\mathrm{Mg}^{2+}$ and decreased $\mathrm{Ca}^{2+}$ concentrations $(3 \times \mathrm{Mg}$ and $0.5 \times$ normal calcium). When the preparation was bathed in ASW containing increased $\mathrm{Ca}^{2+}(3 \times$ normal $)$, the slow synaptic potential increased in size, although a clear change in the fast synaptic potentials was not evident (Fig. $2 B$ ). These 2 results indicate that the slow synaptic potential is mediated chemically
Figure 2. Chemical nature of the synaptic input from $\mathrm{C} 2$ to the MCC. $A$, Effects of bathing the preparation in a solution containing increased $\mathrm{Mg}^{2+}(3 \times$ normal concentration) and decreased $\mathrm{Ca}^{2+}(0.5 \times$ normal concentration): 1 , Synaptic response in a solution of normal artificial seawater $(A S W) ; 2$, blockade of the synaptic response in a solution of high $\mathrm{Mg}^{2+}$ and low $\mathrm{Ca}^{2+} ; 3$, recovery of the synaptic response after washout with a solution of normal ASW. $B$, Effect of increasing $\mathrm{Ca}^{2+}(3 \times$ normal concentration): 1 , Response in a solution of normal ASW; 2 , increased synaptic response in high $\mathrm{Ca}^{2+}$ solution; 3 , the synaptic response returns to normal upon washout with ASW. Experiments in $A$ and $B$ were performed on the same preparation.
$A_{1}$

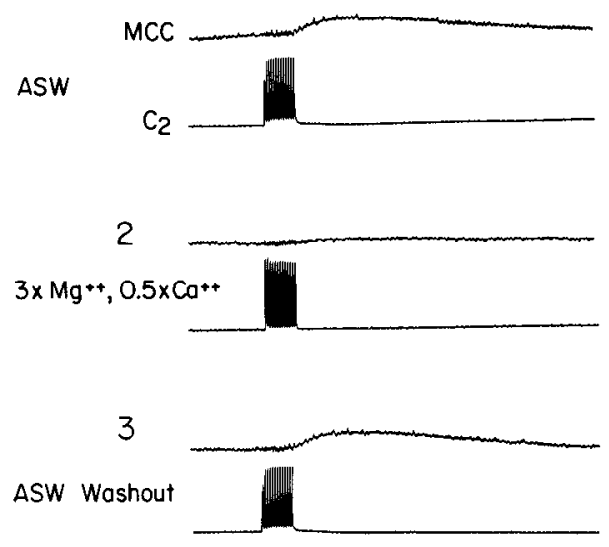

B।

ASW

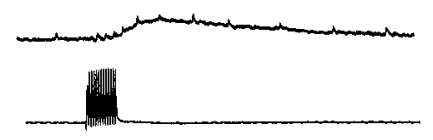

2

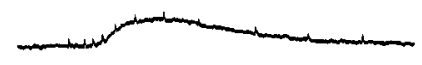

$3 \times \mathrm{CO}^{++}$

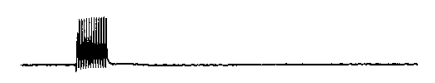

3

ASW Washout 
rather than electrically. Monosynapticity of the synaptic potentials was tested by 2 means: (1) injecting the presynaptic neuron with tetraethylammonium (TEA), which should broaden the presynaptic spike and increase the size of the monosynaptic connection; and (2) bathing the preparation in a solution of high divalent cations $\left(3 \times \mathrm{Mg}^{2+}\right.$ and $\left.3 \times \mathrm{Ca}^{2+}\right)$, which should raise the threshold of possible interneurons and therefore reduce or block polysynaptic responses. In Figure $3 A$, the injections of TEA increase the size of the slow potential. Figure $3 B_{2}$ shows that when the ganglion was bathed in a solution of high divalent cations, stimulation of $\mathrm{C} 2$ no longer evoked the fast potentials, but the slow potential persisted (Fig. 3A). Ono and McCaman (1980) have provided evidence that a neuron termed C3 also makes monosynaptic excitatory connections to the MCC, and that $\mathrm{C} 3$ is electrically coupled to $\mathrm{C} 2$. Our experiment with high divalent cations suggests that the connection of $\mathrm{Cl}$ to the $\mathrm{MCC}$ is not likely to be mediated by $\mathrm{C} 3$, since a high divalent cation solution will raise the threshold of neurons, and all polysynaptic responses that involve spiking interneurons should be reduced or blocked. In addition, while in most preparations it was necessary to fire a burst of $\mathrm{C} 2$ action potentials to detect a postsynaptic response, in some preparations single spikes were sufficient to produce a discrete PSP with constant latency in the MCC (Fig. $3 C$ ). These experiments suggest that the slow excitatory potential is due to a monosynaptic connection to $\mathrm{C} 2$, whereas the fast potentials are evoked polysynaptically. Also consistent with this interpretation is the observation that the application of histamine evokes a similar EPSP in a preparation that is bathed in a solution that blocks synaptic release (see below).

\section{Modulation of the firing of the $M C C$ by the activity of $\mathrm{C} 2$}

Despite the ostensibly weak synaptic effects of $\mathrm{C} 2$ on the metacerebral cell when $\mathrm{C} 2$ was not fired in high-frequency bursts, a relatively low rate of activity of $\mathrm{C} 2$ was capable of modulating the activity of the MCC when the latter was depolarized by a second input. Figure 4 shows an experiment in which cell C2 was fired at approximately 6 spikes/sec by means of injected current pulses that allowed a constant rate of $\mathrm{C} 2$ firing despitc the synaptic input it received. At this rate of firing, $\mathrm{C} 2$ produced only a small synaptic potential that was not capable of triggering an action potential in the MCC (Fig. 4A). However, when a train of spikes was elicited in the MCC by means of a constant depolarizing current pulse (Fig. $4 B_{1}$ ), the slow EPSP significantly increased the number of spikes elicited (Fig. $4 B_{2}$ ). The capacity of the EPSP produced by $\mathrm{C} 2$ to increase the spiking of the MCC was a function of the size of the depolarizing current pulse injected into the MCC. Figure 5 shows the spiking of the MCC in response to the injection of current pulses of different sizes, both when $\mathrm{C} 2$ was fired and when it was inactive. $\mathrm{A} 10 \mathrm{sec}$ pulse of $0.5 \mathrm{nA}$ elicited 7 spikes in the MCC when $\mathrm{C} 2$ was inactive (Fig. 5A1), and elicited 10 spikes when $\mathrm{C} 2$ was fired, an increase of $43 \%$. In contrast, a pulse of $1.0 \mathrm{nA}$ elicited 13 spikes in the $\mathrm{MCC}$ when $\mathrm{C} 2$ was inactive (Fig. $5 B 1$ ), but 28 spikes when $\mathrm{C} 2$ was fired (Fig. $5 B 2$ ), an increase of $115 \%$.

The ability of $\mathrm{C} 2$ to increase the excitability of the MCC was manifest even when $\mathrm{C} 2$ was fired at a rate that failed to produce a recordable synaptic potential in the MCC. Figure $6 \mathrm{~A}$ shows a recording from the MCC in which no synaptic potential was evident when $C 2$ was fired at $0.5 \mathrm{~Hz}$. In Figure $6 B$, intracellular constant current pulses (monitored in the bottom trace) were injected into the MCC to simulate a second synaptic input. Prior to the activation of neuron $\mathrm{C} 2$, these constant current pulses were not able to produce an action potential in the MCC. However, when neuron $\mathrm{C} 2$ was activated, they became suprathreshold, despite the fact that activity of $\mathrm{C} 2$ produced no obvious synaptic potential in the MCC.

Our results on the effects of $\mathrm{C} 2$ on the excitability of the MCC
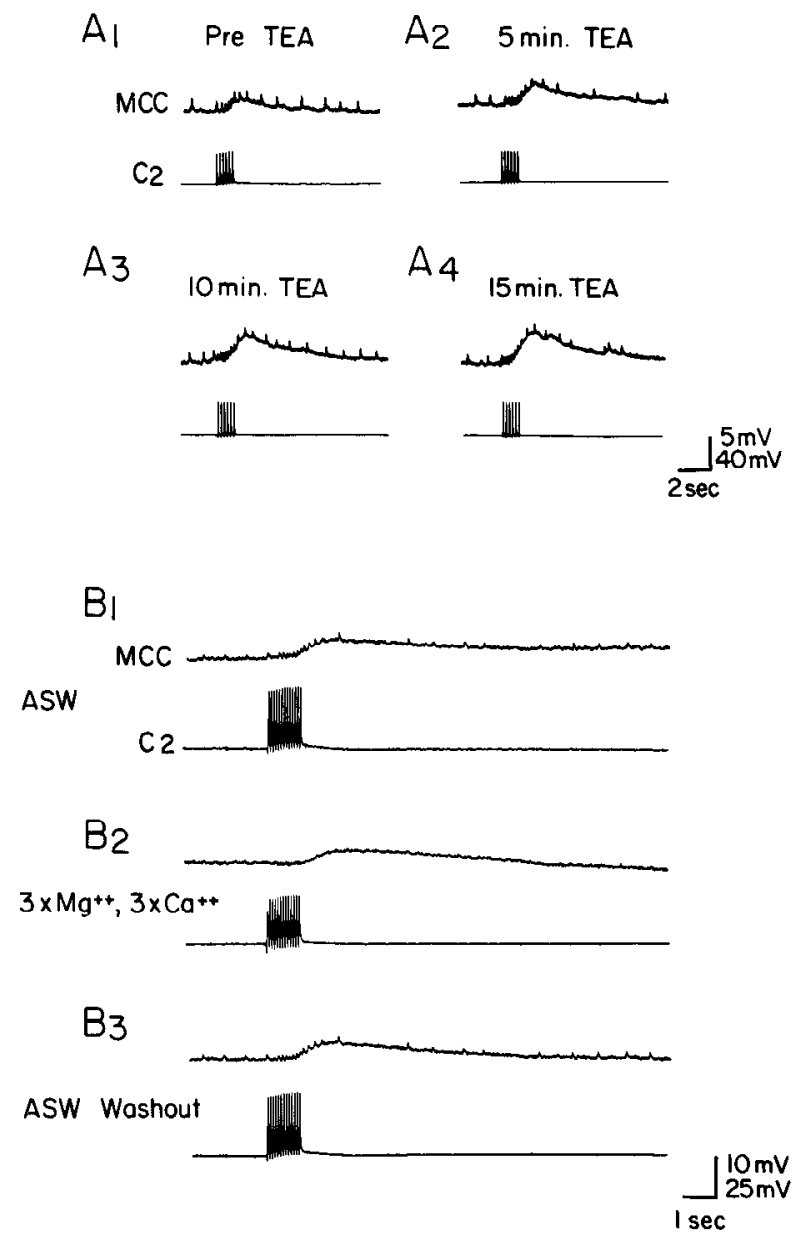

C

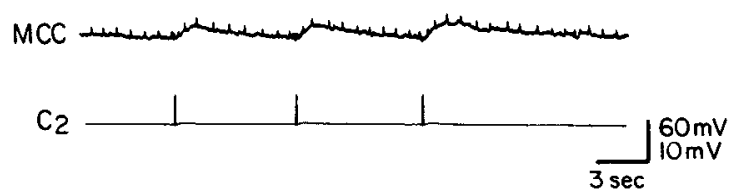

Figure 3. Evidence for the monosynapticity of connections of cell $\mathrm{C} 2$ to the MCC. $A$, Effects of the iontophoretic injection of TEA into $\mathrm{C} 2$. 1, Response of the MCC to a train of 6 action potentials in neuron $\mathrm{C} 2$ prior to the beginning of TEA injections; $2-4$, synaptic potentials after TE $\Lambda$ has been iontophoresed for 5,10 , and $15 \mathrm{~min}$, respectively. $B$, Effect of increased concentration of divalent cations $(3 \times$ normal concentration of $\mathrm{Mg}^{2+}$ and $3 \times$ normal concentration of $\left.\mathrm{Ca}^{2+}\right): 1$, The preparation was bathed in normal ASW and stimulation of $\mathrm{C} 2$ produced a synaptic potential composed of the fast potentials and the slow depolarization; 2 , when the preparation was bathed in a solution containing high divalent cations, the fast potentials disappeared but the slow depolarization persisted; 3, upon return to normal ASW the fast potentials were reinstated. $C$, Example of a case where each action potential in $\mathrm{C} 2$ evoked a slow synaptic potential of constant latency in the MCC.

suggested that $\mathrm{C} 2$ may produce a conductance-decrease EPSP in the MCC. Since decreased conductance EPSPs increase in amplitude with depolarization, this could explain why depolarizing electrotonic pulses became effective in triggering action potentials in the MCC when cell C2 was active, even though the firing of $\mathrm{C} 2$ did not produce visible EPSPs at resting membrane potential. A conductance-decrease EPSP would also explain why, in the presence of the firing of $\mathrm{C} 2$, the excitability of the MCC was greater when the depolarizing pulses injected into 
A

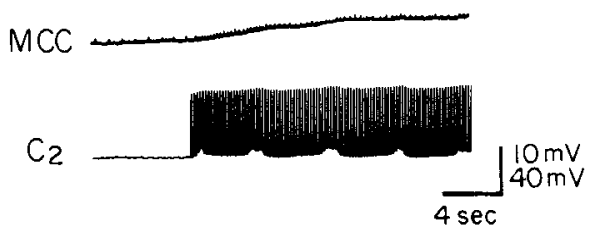

$B_{1}$

$\mathrm{B}_{2}$
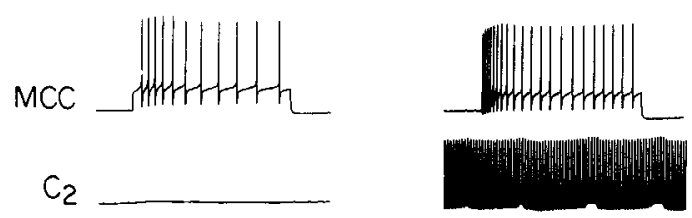

$I _ { M C C } \longdiv { 2 }$

Figure 4. Firing of $\mathrm{C} 2$ at the same rate at which it failed to fire the MCC $(A)$ produces a substantial enhancement of the number of spikes elicited in the MCC in response to a constant current depolarizing pulse. $B$, MCC responses (l) to depolarization in the absence of activity of $\mathrm{C} 2$, and (2) in the presence of the firing of $\mathrm{C} 2$.

it were bigger (for an analysis of a similar phenomenon see Carew and Kandel, 1977).

Slow EPSP is associated with an apparent decreased conductance

In order to measure conductance changes underlying the slow synaptic potentials, we fired a long burst of action potentials in cell $\mathrm{C} 2$ and monitored conductance changes in the MCC by injecting repeated constant current pulses. In Figure $7 A$, we see that, during the slow EPSP, the voltage drop across the membrane caused by the injected current increased significantly, which

Al

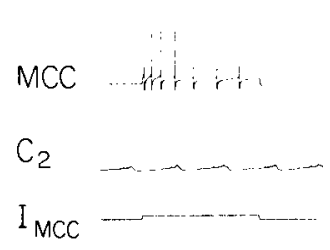

$\mathrm{BI}$

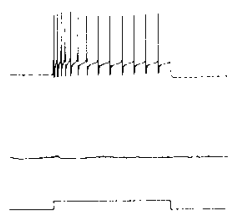

A2

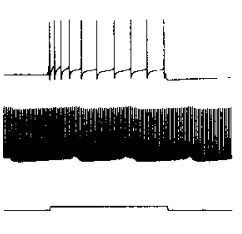

B2

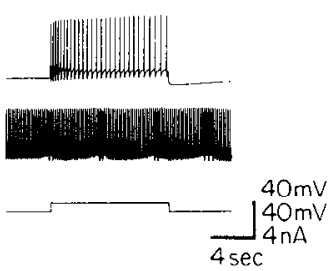

Figure 5. Effects of MCC depolarization on the efficacy of $\mathrm{C} 2$ potentiation of MCC firing. $A$, Intracellular injection of a $0.50 \mathrm{nA}$ current pulse into the MCC in the absence $(1)$ or presence (2) of activity of neuron $\mathrm{C} 2$. $B$, Injection of a $1.0 \mathrm{nA}$ current pulse into the $\mathrm{MCC}$ in the absence $(1)$ or presence (2) of $\mathrm{C} 2$ activity. When a small current pulse was injected into the MCC, stimulation of $\mathrm{C} 2$ added 3 action potentials to the firing of the MCC; whereas when a larger current pulse was injected, stimulation of the $\mathrm{C} 2$ added 15 action potentials to the burst in the MCC. Firing of $\mathrm{C} 2$ by itself at the rate used in this experiment depolarized the MCC by about $4 \mathrm{mV}$ and never elicited spikes.

$A$
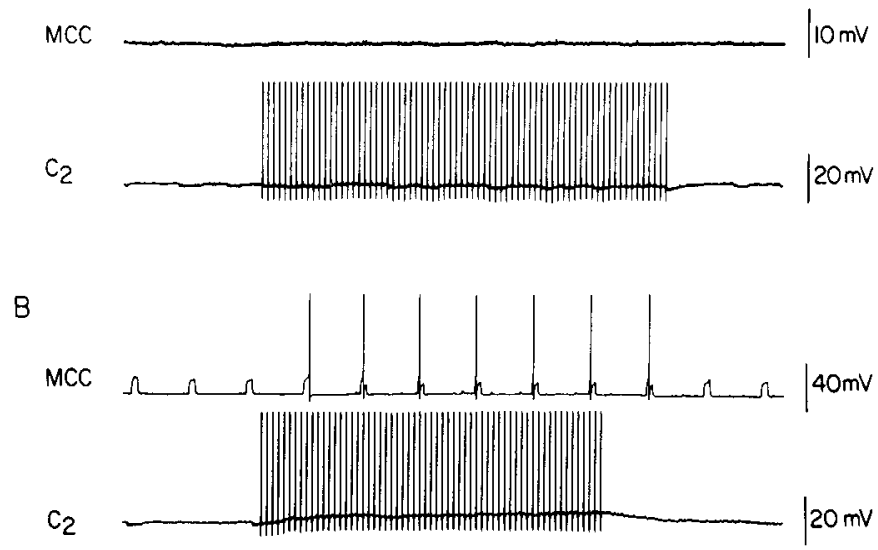

I

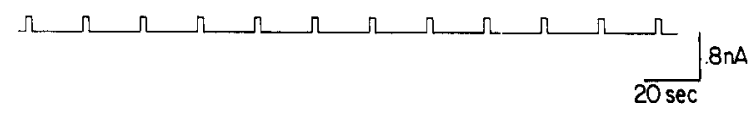

Figure 6. Effects of a very low rate of $\mathrm{C} 2$ activity on the threshold for initiation of action potentials by the MCC. $A$, When $\mathrm{C} 2$ was fired at a very low rate, it failed to produce any obvious synaptic potential in the MCC. $B$, A constant current pulse that did not produce an action potential in the MCC became suprathreshold when cell $\mathrm{C} 2$ was stimulated at the frequency that, in $A$, did not produce any measurable EPSP. Current injected into the MCC is indicated in $I$.

A

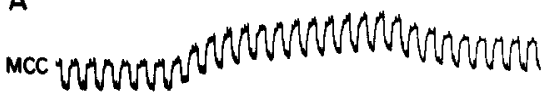

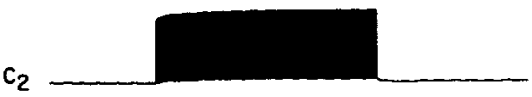

B

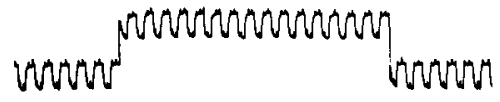

C
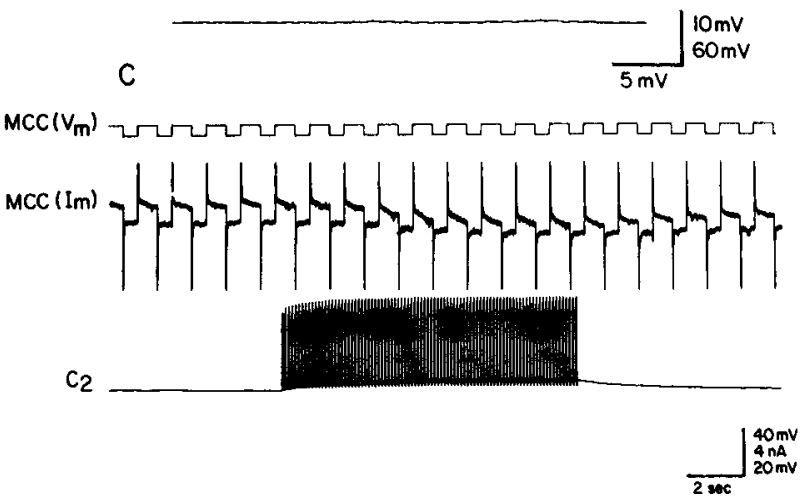

Figure 7. Conductance changes in the MCC during the slow EPSP evoked by stimulation of $\mathrm{C} 2$. $A$, Constant current pulses injected into the MCC increased in amplitude during the slow EPSP. $B$, The MCC was depolarized by an intracellular current injection to the same membrane potential recorded during the EPSP in $A$. Little or no change of the input resistance of the MCC was observed. $C$, Under voltage clamp, the current required to move the membrane potential of the MCC by $10 \mathrm{mV}$ decreased during the slow EPSP produced by activation of $\mathrm{C} 2$. 


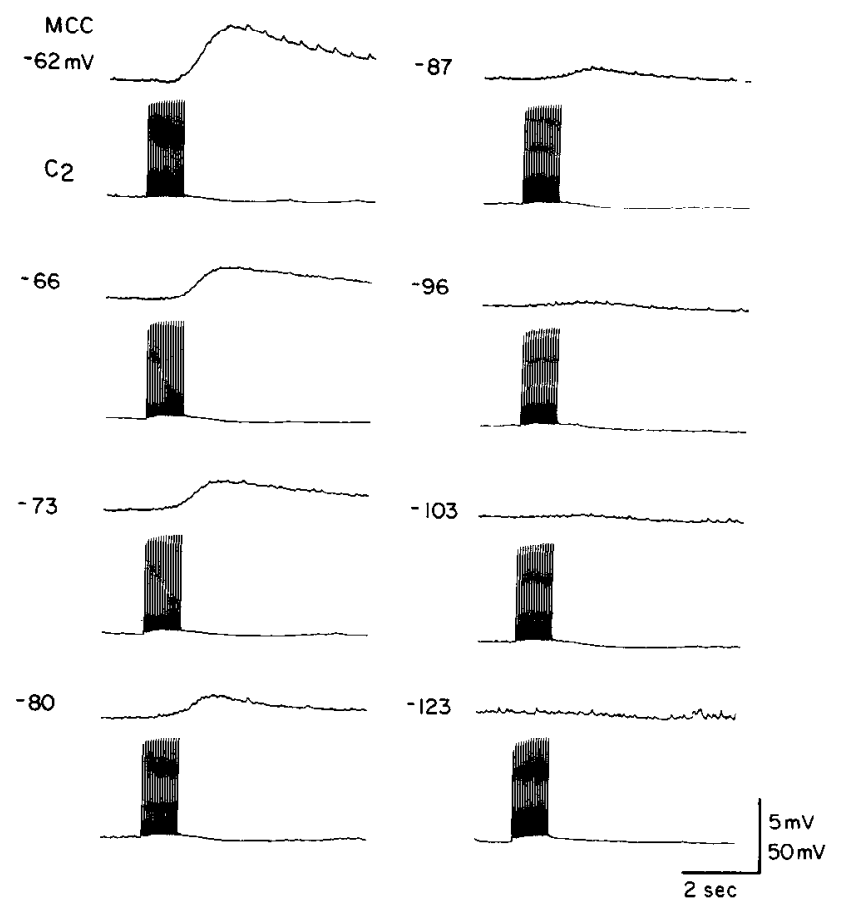

Figure 8. Effects of hyperpolarizing the MCC on the amplitude of the slow EPSP evoked by the stimulation of cell C2. Note that hyperpolarization of the MCC led to the abolition, but not reversal, of the EPSP.

suggests that the EPSP is associated with a decrease of membrane conductance. Since the MCC of Aplysia exhibits inwardgoing (anomalous) rectification (Weiss and Kupfermann, 1976; see also Fig. 12), we investigated whether the change in conductance of the MCC during the slow synaptic potential might have been due to the depolarization, which could have brought the MCC into a region where it showed a higher input resistance. Figure $7 B$ shows an experiment performed on the same pair of cells as those in Figure $7 \mathrm{~A}$. Intracellular current injection was used to depolarize the MCC to the same membrane potential that was recorded during the EPSP evoked by $\mathrm{C} 2$. There was little or no change of input resistance over this range of depolarization. This suggestcd that the EPSP was indecd a decreased conductance EPSP, a conclusion further supported by voltageclamp experiments in which membrane conductance was measured by the amount of current needed to produce a fixed voltage step. Under these conditions, membrane potential was controlled and therefore did not contribute an unknown variable to the measurement. As Figure $7 C$ shows, during the slow EPSP evoked in the MCC by stimulating cell $\mathrm{C} 2$, the current pulses required to move the membrane potential of the MCC by 10 $\mathrm{mV}$ became $50 \%$ smaller, i.e., the membrane conductance decreased during the EPSP.

\section{Slow EPSP is voltage-dependent}

In order to understand the functional properties of the EPSP, we investigated its characteristics as a function of membrane potential. As expected for a decreased conductance EPSP, its amplitude became smaller when the MCC was hyperpolarized (Fig. 8). However, even when the cell was hyperpolarized to below $-100 \mathrm{mV}$, the EPSP was still present; with further hyperpolarization it was abolished, but it never reversed. In order to ascertain whether the disappearance of the synaptic potential when the MCC was strongly hyperpolarized was accompanied by abolition of the change in membrane conductance, we measured changes of conductance during the EPSP while the MCC was voltage-clamped over a wide range of membrane potentials

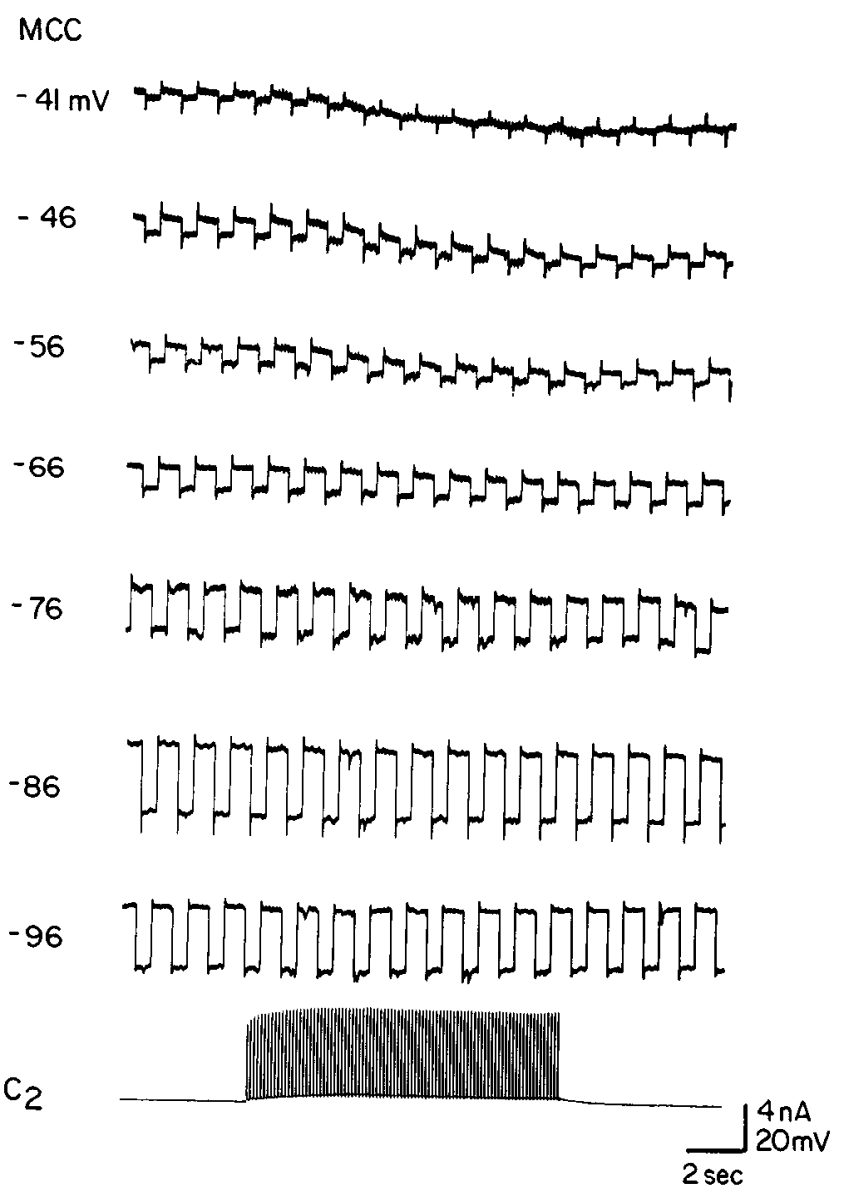

Figure 9. Measurements of conductance changes in voltage-clamped MCC during the slow EPSP produced by stimulation of C2. The MCC was held clamped at various potentials (ranging from -41 to $-96 \mathrm{mV}$ ). At each potential, the cell was repeatedly stepped $10 \mathrm{mV}$. At hyperpolarized levels, both the slow inward current and the change in the current required to step the cell by $10 \mathrm{mV}$ disappeared. Note that as the cell was held at more hyperpolarized potentials, the current pulses required to step the $\mathrm{MCC}$ by $10 \mathrm{mV}$ increased in size, reflecting the increasing membrane conductance at hyperpolarized levels (anomalous or inward rectification). Bottom trace shows the firing of $\mathrm{C} 2$ for each of the membrane potentials of the MCC in the traces above.

(Fig. 9). In the depolarized range, firing of $\mathrm{C} 2$ produced an inward current, accompanied by a decrease in the size of current pulses needed to produce a constant voltage step. When the MCC was strongly hyperpolarized, no inward current was evoked by stimulation of cell $\mathrm{C} 2$, nor was there a change in the number of current pulses required for constant voltage steps. In other words, when the MCC was hyperpolarized, both the EPSP and the conductance change disappeared.

One possible explanation of why the EPSP could not be inverted is that the presynaptic terminals of $\mathrm{C} 2$ are electrically coupled to the MCC. Therefore, strong hyperpolarization of the MCC could conceivably hyperpolarize the terminals of $\mathrm{C} 2$ to the point that transmitter release would be suppressed. In a number of preparations, hyperpolarization of presynaptic cells has been shown to reduce transmitter release (Klein et al., 1980; Nicholls and Wallace, 1978; Shapiro et al., 1980; Shimahara and Peretz, 1978; Shimahara and Tauc, 1975), and we have found that, when $\mathrm{C} 2$ was hyperpolarized, the synaptic potential produced in the MCC was reduced or abolished (Fig. 10). To investigate whether hyperpolarization of the MCC affected the release of transmitter from $\mathrm{C} 2$, we took advantage of the long duration of the EPSP that it produces. Figure $11 A$ shows that, 
A

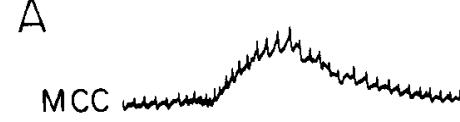

$+8 \mathrm{mV}$

$\mathrm{C}$

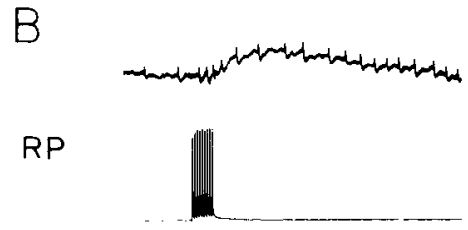

C

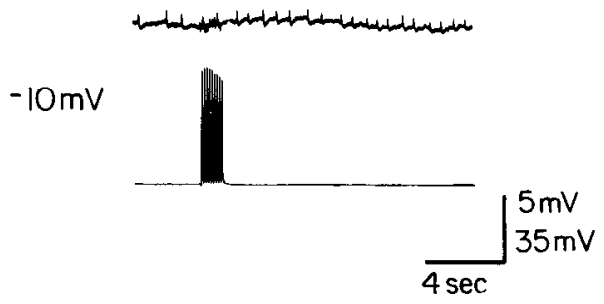

Figure 10. Effect of varying the holding membrane potential of $\mathrm{C} 2 \mathrm{on}$ the EPSP evoked by the activity of C2 in the MCC. Neuron C2 was fired using a train of square current pulses of fixed duration and frequency. The amplitude of the current pulses was adjusted so that at each holding level one pulse produced one action potential. The amplitude of the slow EPSP was biggest when C2 was depolarized $8 \mathrm{mV}$ above the resting potential $(A)$, intermediate when $\mathrm{C} 2$ was held at resting membrane potential $(R P)(B)$, and almost abolished when $\mathrm{C} 2$ was hyperpolarized by $10 \mathrm{mV}(C)$.

when the metacerebral cell is at resting potential, a burst of spikes in C2 produces the characteristic slow EPSP, together with the fast EPSPs that appear to be polysynaptic (see above). When the MCC was hyperpolarized by $35 \mathrm{mV}$, the slow monosynaptic EPSP was abolished without a concomitant abolition of the polysynaptic response (Fig. $11 B$ ). This indicated that, if hyperpolarization of the MCC had an effect on the synaptic terminals of $\mathrm{C} 2$, the effect would have to be selective to the terminals on the MCC. That this is not the case can be seen in Figure $11 C$. The MCC was hyperpolarized by $35 \mathrm{mV}$ before and during a burst of action potentials in $\mathrm{C} 2$, but was released from hyperpolarization at the end of the $\mathrm{C} 2$ burst. When the MCC was released from hyperpolarization, the slow EPSP (similar to the one that occurred at resting membrane potential) was seen, which indicates that transmitter release must have occurred from $\mathrm{C} 2$ when the MCC was hyperpolarized. In control experiments in which we released the MCC from similar hyperpolarization in the absence of firing of $\mathrm{C} 2$, no significant anodal break from hyperpolarization was observed. This experiment indicates that our inability to reverse the slow EPSP when the MCC was hyperpolarized was not due to an artifact of electrical coupling between the terminals of the MCC and $\mathrm{C} 2$.

An alternative explanation of the failure of hyperpolarization to reverse the EPSP is that the current injected into the soma
A

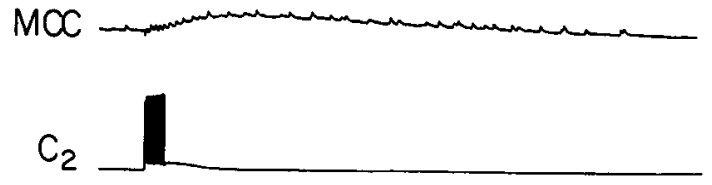

B
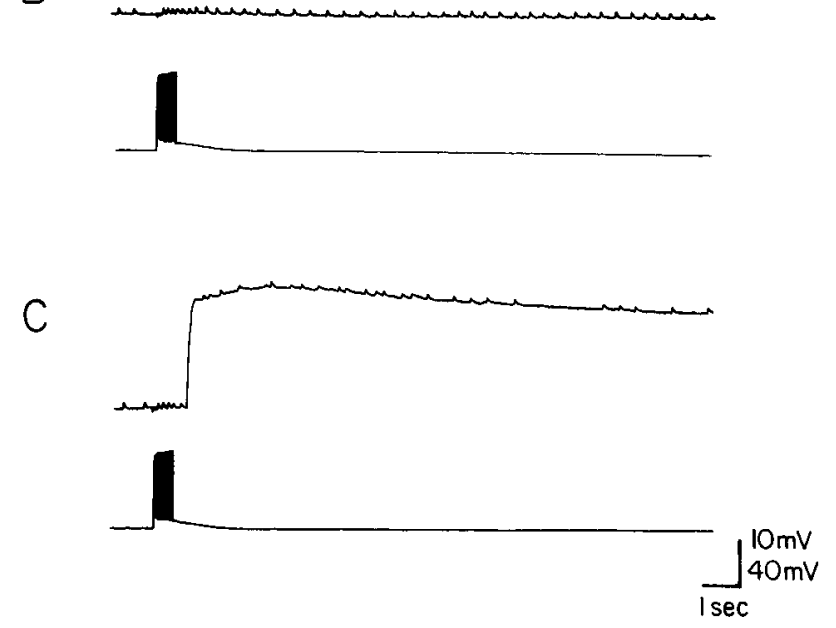

Figure 11. Effect of hyperpolarizing the MCC during transmitter release from $\mathrm{C} 2$. $A$, When the $\mathrm{MCC}$ was held at resting membrane potential, fring of $\mathrm{C} 2$ produced both the fast polysynaptic and the slow monosynaptic EPSPs. $B$, When the MCC was hyperpolarized $35 \mathrm{mV}$ below resting potential, firing of $C 2$ evoked only the fast polysynaptic component. $C$, When the MCC was hyperpolarized to the same extent as in $B$, but the hyperpolarization was released at the end of the burst of action potentials in $\mathrm{C} 2$, both the fast and slow components of the EPSP were seen.

of the MCC failed to effectively hyperpolarize the synaptic region of the cell. This could be due to the pronounced inward rectification of the MCC (Weiss and Kupfermann, 1976). As the MCC is hyperpolarized, its input resistance markedly decreases, creating a current shunt through the soma and proximal processes of the cell. Therefore, to obtain an improved spaceclamp of the neuron, we performed a series of voltage-clamp studies in which the MCC was axotomized within $300 \mu \mathrm{m}$ of the cell body. The current-voltage relation was determined by stepping from a holding membrane potential of $-60 \mathrm{mV}$ to various other potentials, and measuring the current at the end of a 5 sec pulse when the current had achieved a steady state. Current-voltage relations were determined in normal ASW and in the presence of bath-applied histamine $\left(10^{-4} \mathrm{M}\right)$. The difference between the current-voltage curves in the presence and the absence of histamine was taken to represent the histamine-induced current. Under these conditions, the histamine-induced current again did not reverse. It disappeared at approximately $-80 \mathrm{mV}$ (Fig. 12). This suggested that we might be dealing with a decreased potassium-conductance EPSP that does not reverse hecause it has some rectifying or voltage-dependent properties. Alternatively, these results could be due to an increase of conductance to calcium or sodium if these conductances are highly voltage-dependent. We found, however, that under voltage clamp, histamine-induced inward current persisted in sodium- 


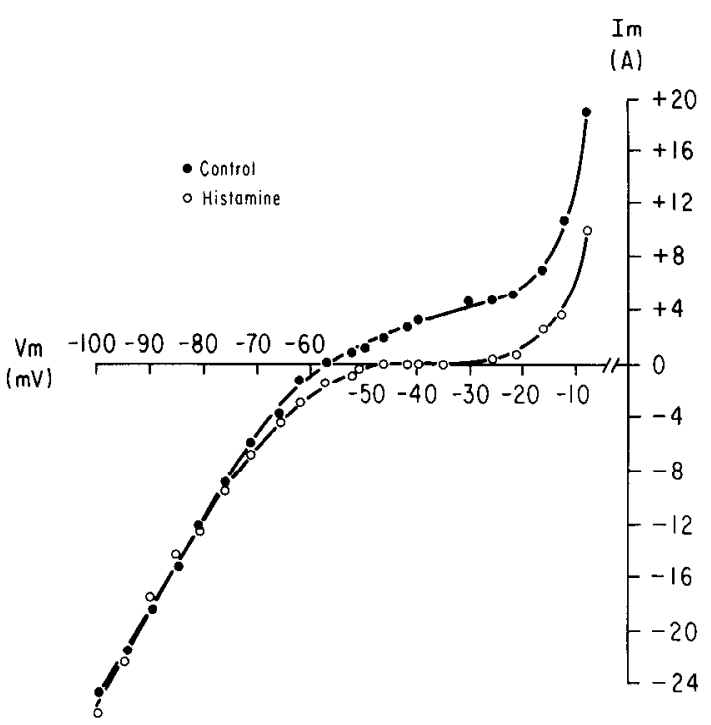

Figure 12. Effects of histamine on the I-V relations in the MCC. The MCC was held at $-60 \mathrm{mV}$ and the $I-V$ curve was generated by stepping the cell to various membrane potentials for 5 sec. The current was measured at the end of the $5 \mathrm{sec}$ step, when the currents attained a steady state.

free solutions (substituted for by Tris or sucrose). Experiments on the role of calcium gave inconsistent results. In 2 experiments, the histamine-induced current persisted in the presence of the calcium channel-blocker cobalt $(30 \mathrm{~mm})$, but in one experiment, cobalt appeared to block the histamine-induced cur- rent. In calcium-free solutions (supplemented with $10 \mathrm{~mm}$ EGTA), the histamine current persisted in one experiment and was blocked in another. Similar inconsistent sensitivity to external calcium has been observed for serotonin in decreasing a potassium current in sensory neurons of Aplysia (M. Klein, personal communication; see also Pollock et al., 1985; Walsh and Byrne, 1985).

\section{Histamine-induced current in the MCC is dependent on external potassium concentration}

To examine more directly the hypothesis that this EPSP is mediated by a decreased potassium conductance, we investigated the effect of varying the potassium concentration in the solution bathing the preparation (Fig. 13). In order to block possible polysynaptic actions of histamine, these experiments were performed in seawater supplemented with $100 \mu \mathrm{M}$ TTX and $\mathrm{Mg}^{2+}$ substituted, mole for mole, for $\mathrm{Na}^{+}$, sufficient to bring the final $\mathrm{Mg}^{2+}$ concentration to $150 \mathrm{~mm}$. Potassium ion concentrations of 10,60 , and $100 \mathrm{~mm}$ were obtained by equimolar substitution of potassium for sodium. Three experiments were performed for each of these potassium concentrations. We found that in high concentrations of potassium we were able to reverse the synaptic current induced by histamine application. This reversal, similar to the disappearance of the synaptic current in normal (10 $\mathrm{mm})$ potassium, corresponded to the predicted Nernst equilibrium potential for potassium (Fig. 13B). However, even when the synaptic current reversed in high potassium, it did not follow the expected ohmic relations; i.e., when the cell was stepped to hyperpolarized potentials greater than the reversal potential, the amplitude of the reversed current failed to increase. In fact, as the cell was stepped to more hyperpolarized potentials, the histamine-induced current got smaller and eventually returned to zero.

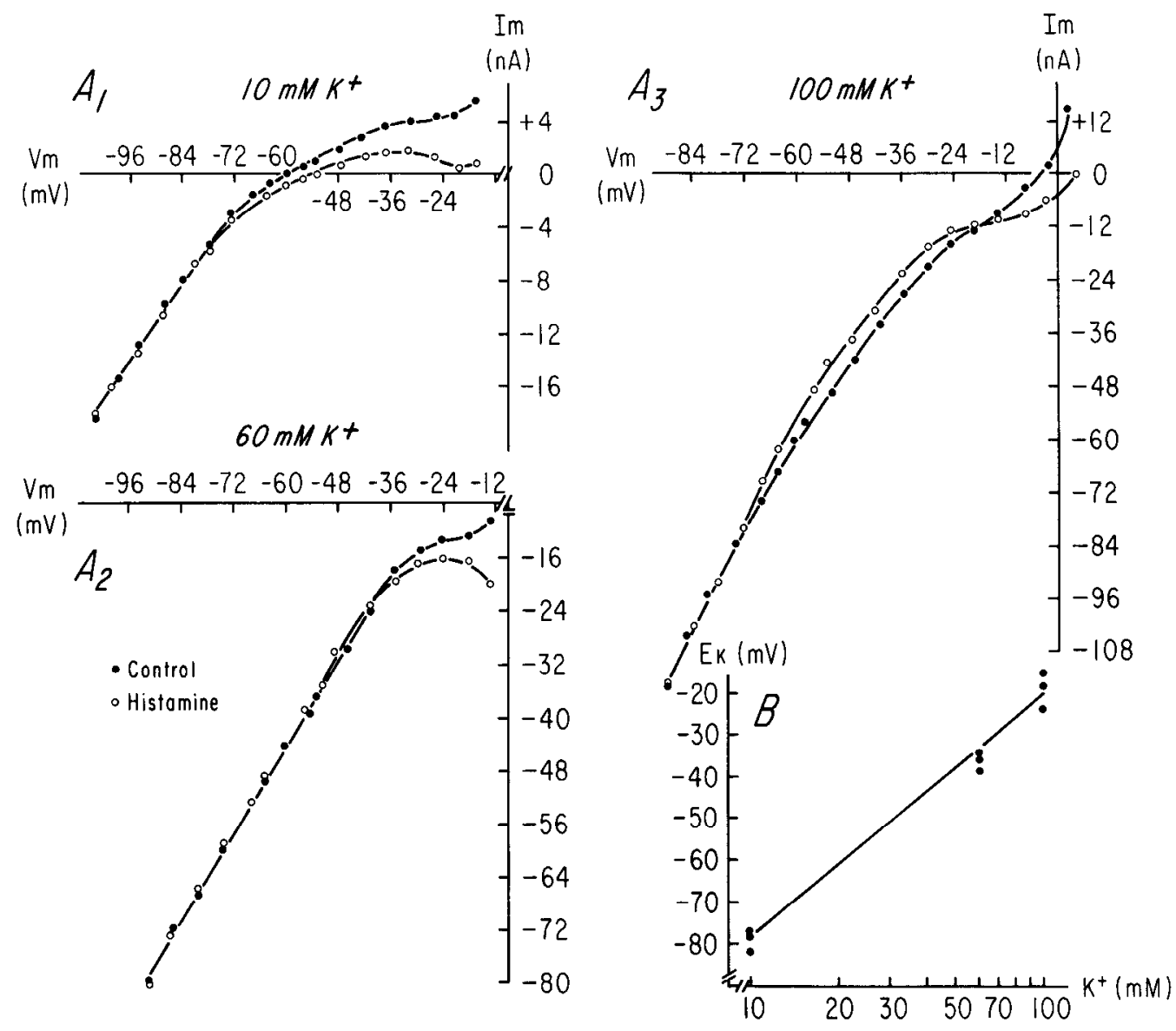

Figure 13. Effects of histamine and of varying external concentrations of potassium (10 mM in $A_{i}, 60 \mathrm{~mm}$ in $A_{2}$, and $100 \mathrm{mM}$ in $A_{3}$ ) on the I-V relations of the MCC. The MCC was held at $-60 \mathrm{mV}$ and the $I-V$ curve was generated by stepping the cell to various membrane potentials for $5 \mathrm{sec}$, and measuring the current at the end of the step. B, Solid line represents the calculated equilibrium potential for $\mathrm{K}^{+}$, based on the Nernst equation, assuming a $K_{\mathrm{i}}$ of $232 \mathrm{~mm}$ (Sato et al., 1968). Dots represent the distribution of the measured reversal potentials of the histamine-induced current at 3 different external concentrations of potassium. Three experiments were performed for each of the following concentrations: 10,60 , and $100 \mathrm{~mm}$. 


\section{Discussion}

The initial focus of this research was on locating neurons that might constitute elements of a central arousal system in Aplysia. The existence of a central arousal system was hypothesized on the basis of 2 observations. First, food stimuli potentiate a variety of responses, including feeding, locomotion, and cardiovascular responses. Second, the potentiating effects greatly outlast the initial presentation of the food. Potentiation of the different response systems is mediated by specialized neurons, each of which appears to be devoted to a single class of closely related behaviors. We term these neurons "arousal executor cells." One such neuron is the metacerebral cell, which potentiates consummatory aspects of feeding behavior by both peripheral actions on buccal muscles (Weiss et al., 1975, 1978a, 1979) and central actions on motor neurons and a putative central pattern generator that drives rhythmic feeding responses. Conceived of in the simplest terms, an element of a central arousal system should have the following characteristics:

1. It should excite arousal executor cells.

2. It should have widespread effects or be part of a system of interconnected neurons that drive a number of cells.

3. It should be activated by stimuli that evoke an arousal state.

4. It should produce effects that outlast the stimuli that excite it to action.

In this article, we have explored the first criterion and provide evidence that the $\mathrm{MCC}$ is excited by identified histaminergic neuron C2. The excitation is due to a slow EPSP, as well as a relatively weak input consisting of fast EPSPs that are blocked in the presence of high divalent cations and are clearly polysynaptic. The slow EPSP appears to be monosynaptic, on the basis of observations that it (1) persists in a high divalent cation solution, (2) is enhanced when the presynaptic spike is broadened by TEA, and (3) is mimicked by application of histamine, the likely transmitter of neuron C2 (McCaman and McKenna, 1978; McCaman and Weinreich, 1982; Ono and McCaman, 1980; Schwartz et al., 1986; Weinreich, 1977, 1978; Weinreich and $\mathrm{Yu}, 1977$; Weinreich et al., 1975).

The slow EPSP that $\mathrm{C} 2$ produces in the MCC has all of the characteristics of a modulatory, as opposed to a mediating, synaptic potential (Kupfermann, 1979). First, the slow EPSP has a very slow onset and slow decay. Second, the slow EPSP appears to involve a nonconventional ionic conductance. Our evidence indicates that the EPSP is associated with a decreased conductance, which can function to amplify other synaptic inputs to the cell (Byrne, 1981; Carew and Kandel, 1977; Weight, 1974). Furthermore, the slow EPSP shows a strong voltage-dependence. Therefore, the synaptic current is small when the MCC is at resting potential, and totally disappears when the MCC is strongly hyperpolarized. This property can result in the enhancement of inhibitory inputs that hyperpolarize the MCC and drive it into the region of membrane potential where the slow EPSP is decreased (see Kandel and Tauc, 1966, for a similar property that arises as a consequence of anomalous rectification in the MCC of Helix). Conversely, in the presence of the slow EPSP, a decrease of a tonic IPSP will result in an enhanced depolarization because the EPSP will be amplified as the membrane potential depolarizes. The voltage-dependence of the slow EPSP could also explain the observation that, at low rates of firing of $\mathrm{C} 2$, the MCC at resting potential shows enhanced excitability to depolarizing inputs, even though $\mathrm{C} 2$ fires at a rate too low to produce any shift of membrane potential. With a more intense activity of $\mathrm{C} 2$, a substantial depolarization of the MCC occurs, even at resting potential, which is close to the potential at which no synaptic current is present. This may result from the fact that, because the EPSP is due to a decreased conductance, as the cell begins to depolarize it moves into a region in which an enhanced synaptic current exists. In other words, the synaptic potential has self-regenerative properties (Carew and Kandel, 1977).

Voltage-clamp experiments in which the external concentration of potassium ions was varied suggest that the histamineinduced slow synaptic potential is due, at least in large part, to a decreased conductance to potassium, and this conclusion is consistent with the evidence of McCaman and Weinreich (1985) on the very slow EPSPs produced by $\mathrm{C} 2$. Failure of the synaptic currents to clearly reverse at potentials hyperpolarized relative to the potassium equilibrium potential may be, to some extent at least, a consequence of constant field rectification (Goldman, 1943) which arises because of the uneven distribution of extracellular $\mathrm{K}^{+}$and intracellular $\mathrm{K}^{+}$(see, e.g., Siegelbaum et al., 1982). Consistent with this interpretation is the observation that a reversal of the histamine-induced current was observed when the external potassium ion concentration was raised. But even under those conditions, the inward current behaved anomalously and did not increase linearly with increasing hyperpolarization of the MCC. This suggests that, in addition to constant field rectification, the nonlinear properties of the slow EPSP may be due to voltage-gating of the relevant channels. It is also possible that the rectification is partly due to blockage of the potassium channel by sodium ions when the cell is strongly hyperpolarized (for a review of this mechanism, see Hille, 1984). It should be pointed out, however, that bath-applied histamine, under our experimental conditions, need not necessarily affect the same receptors that are activated by normal synaptic input.

In many respects the behavior of the histamine-modulated channels resembles that of the $\mathrm{S}$ channels that exist on sensory neurons of Aplysia, which are closed by serotonin (Klein and Kandel, 1978, 1980; Klein et al., 1982; Shuster et al., 1985; Siegelbaum et al., 1982), and the neuropeptides $\mathrm{SCP}_{A}$ and $\mathrm{SCP}_{B}$ (Abrams et al., 1984). In preliminary experiments we have found that serotonin also evokes a slow decreased conductance in the $\mathrm{MCC}$, which raises the possibility that $\mathrm{S}$ channels also exist on the MCC or that the histamine-modulated channels are identical to $\mathrm{S}$ channels. Consistent with the interpretation that the MCC may contain $S$ channels are the observations that the closing of $\mathrm{S}$ channels is mediated by a cAMP-dependent protein kinase (Klein and Kandel, 1978; Shuster et al., 1985; Siegelbaum et al., 1982) and that cAMP also may decrease membrane conductance in the MCC (Drake and Treistman, 1980; Treistman and Drake, 1979). In addition, similar to the conductance we have studied, the modulation of potassium conductance of mechanosensory neurons by serotonin can be affected by external calcium (Pollock et al., 1985; Walsh and Byrne, 1985). The histamine-induced current in the MCC also has some similarities to the slow depolarization induced by muscarine in sympathetic ganglion cells of the bullfrog. The muscarine-induced current is primarily due to a decrease of a calcium-independent potassium conductance (Adams et al., 1982) but may also have a component mediated by a decrease of a calciumdependent potassium current (Pennefather et al., 1985).

In neurons of the vertebrate myenteric plexus, histamine (Grafe et al., 1980) and serotonin (Nemeth et al., 1984) also decrease potassium conductance. In myenteric neurons, however, the decreased potassium conductance is the calcium-dependent potassium conductance (see also Haas and Konnerth, 1983). For this reason, in the myenteric plexus, serotonin greatly reduces the spike-induced afterhyperpolarization that ordinarily severely limits the ability of the cells to exhibit repetitive spikes at high frequency. Judging by the absence of significant changes in the afterhyperpolarization of MCC spikes, the histamineinduced slow EPSP has little or no effect on the calcium-dependent potassium current. This is consistent with our finding that even in the presence of the slow EPSP, the MCC does not generally show high-frequency spike activity. Further, the MCC 
normally fires at a low frequency (Kupfermann and Weiss, 1982) and is able to exert physiological effects even at rates of activity as low as 0.4 spikes/sec (Weiss et al., 1978a, b).

Regardless of the mechanism of the slow EPSP produced by $\mathrm{C} 2$, its existence in the $\mathrm{MCC}$ clearly makes $\mathrm{C} 2$ a candidate as an element of the system mediating food arousal in Aplysia. In subsequent articles, we examine other features of $\mathrm{C} 2$ and report that some, but not all, features of the neuron are consistent with its being an element of an integrated central arousal system.

\section{References}

Abrams, T. W., V. F. Castellucci, J. S. Camardo, E. R. Kandel, and P. E. Lloyd (1984) Two endogenous neuropeptides modulate the gill and siphon withdrawal reflex in Aplysia by presynaptic facilitation involving cAMP-dependent closure of a serotonin-sensitive potassium channel. Proc. Natl. Acad. Sci. USA 81: 7956-7960.

Adams, P. R., D. A. Brown, and A. Constanti (1982) Pharmacological inhibition of the M-current. J. Physiol. 332: 223-262.

Byrne, J: H. (1981) Simulation of the neural activity underlying a short-term modification of inking behavior in Aplysia. Brain Res. 204: 200-203.

Carcw, T. J., and E. R. Kandcl (1977) Inking in Aplysia californica: III. Two different synaptic conductance mechanisms for triggering central program for inking. J. Neurophysiol. 40: 721-734.

Chiel, H. J., K. R. Weiss, and I. Kupfermann (1986) An identified histaminergic neuron modulates feeding motor circuitry in Aplysia. J. Neurosci. 6: 2427-2750.

Dieringer, N., J. Koester, and K. R. Weiss (1978) Adaptive changes in heart rate of Aplysia californica. J. Comp. Physiol. 123: 11-21.

Drake, P. F., and S. N. Treistman (1980) Alteration of neuronal activity in response to cyclic nucleotide agents in Aplysia. J. Neurobiol. 11: 471-482.

Eisenstadt, M., J. E. Goldman, E. R. Kandel, H. Koike, J. Koester, and J. H. Schwartz (1973) Intrasomatic injection of radioactive precursors for studying transmitter synthesis in identified neurons of Aplysia californica. Proc. Natl. Acad. Sci. USA 70: 3371-3375.

Gerschenfeld, H. M., and D. Paupardin-Tritsch (1974) On the transmitter function of 5-hydroxytryptamine at excitatory and inhibitory monosynaptic junctions. J. Physiol. (Lond.) 243: 457-481.

Gerschenfeld, H. M., M. Hamon, and D. Paupardin-Tritsch (1978) Release of endogenous serotonin from two identified serotonin-containing neurones and the physiological role of serotonin reuptake. J. Physiol. (Lond.) 274: 265-278.

Goldman, D. E. (1943) Potential, impedance and rectification in membranes. J. Gen. Physiol. 27: 37-60.

Grafe, P., C. J. Mayer, and J. D. Wood (1980) Synaptic modulation of calcium-dependent potassium conductance in myenteric neurones in the guinea-pig. J. Physiol. (Lond.) 305: 235-248.

Haas, H. L., and A. Konnerth (1983) Histamines and noradrenaline decrease calcium-activated potassium conductance in hippocampal pyramidal cells. Nature $302: 432-434$.

Hille, B. (1984) Ionic Channels of Excitable Membranes, Sinauer, Sunderland, MA.

Jahan-Parwar, B., and S. M. Fredman (1976) Cerebral ganglion of Aplysia: Cellular organization and origin of nerves. Comp. Biochem. Physiol. 54A: 347-357.

Kandel, E. R., and L. Tauc (1966) Anomalous rectification in the metacerebral giant cells and its consequences for synaptic transmission. J. Physiol. (Lond.) 183: 287-304.

Klein, M., and E. R. Kandel (1978) Presynaptic modulation of voltagedependent $\mathrm{Ca}^{++}$current: Mechanism for behavioral sensitization in Aplysia californica. Proc. Natl. Acad. Sci. USA 75: 3512-3516.

Klein, M., and E. R. Kandel (1980) Mechanism of calcium current modulation underlying presynaptic facilitation and behavioral sensitization in Aplysia. Proc. Natl. Acad. Sci. USA 77: 6912-6916.

Klein, M., J. Camardo, and E. R. Kandel (1982) Serotonin modulates a specific potassium current in the sensory neurons that show presynaptic facilitation in Aplysia. Proc. Natl. Acad. Sci. USA 79: 57135717.

Klein, M., E. Shapiro, and E. R. Kandel (1980) Synaptic plasticity and modulation of the $\mathrm{Ca}^{2+}$ current. J. Exp. Biol. 89: 117-157.

Koch, U. T., J. Koester, and K. R. Weiss (1984) Neuronal mediation of cardiovascular effects of food arousal in Aplysia. J. Neurophysiol. 51: 126-135.
Kupfermann, I. (1974) Feeding behavior in Aplysia: A simple system for the study of motivation. Behav. Biol. 10: 1-26.

Kupfermann, I. (1979) Modulatory actions of neurotransmitters. Annu. Rev. Neurosci. 2: 447-465.

Kupfermann, I., and K. R. Weiss (1981) The role of serotonin in arousal of feeding behavior of Aplysia. In Serotonin Neurotransmission and Behavior, A. Gelperin and B. Jacobs, eds., pp. 255-287, M.I.T. Press, Cambridge, MA.

Kupfermann, I., and K. R. Weiss (1982) Activity of an identified serotonergic neuron in free moving Aplysia correlates with behavioral arousal. Brain Res. 241: 334-337.

McCaman, R. E., and D. G. McKenna (1978) Monosynaptic connections between histamine-containing neurons and their various follower cells. Brain Res. 141: 165-171.

McCaman, R. E., and D. Weinreich (1982) On the nature of histamine mediated slow hyperpolarizing synaptic potentials in identified molluscan neurons. J. Physiol. (Lond.) 328: 485-506.

McCaman, R. E., and D. Weinreich (1985) Histaminergic synaptic transmission in the cerebral ganglion of Aplysia. J. Neurophysiol. 53: 1016-1037.

Nemeth, P. R., C. A. Ort, and J. D. Wood (1984) Intracellular study of effects of histamine on electrical behaviour of myenteric neurones in guinea-pig small intestine. J. Physiol. (Lond.) 355: 411-425.

Nicholls, J., and B. G. Wallace (1978) Modulation of transmission at an inhibitory synapse in the central nervous system of the leech. $J$. Physiol. (Lond.) 281: 157-170.

Ono, J. K., and R. E. McCaman (1980) Identification of additional histaminergic neurons in Aplysia: Improvement of single cell isolation techniques for in tandem physiological and chemical studies. Neuroscience 5: 835-840.

Pennefather, P., B. Lancaster, P. R. Adams, and R. A. Nicoll (1985) Two distinct Ca-dependent $\mathrm{K}$ currents in bullfrog sympathetic ganglion cells. Proc. Natl. Acad. Sci. USA 82: 3040-3044.

Pollock, J. D., L. Bernier, and J. S. Camardo (1985) Serotonin and cyclic adenosine $3^{\prime}: 5^{\prime}$-monophosphate modulate the potassium current in tail sensory neurons in the pleural ganglion of Aplysia. J. Neurosci. 5: 1862-1871.

Rosen, S. C., K. R. Weiss, J. L. Cohen, and I. Kupfermann (1982) Interganglionic cerebral-buccal mechanoafferents of Aplysia: Receptive fields and synaptic connections to different classes of neurons involved in feeding behavior. J. Neurophysiol. 48: 271-288.

Rosen, S. C., I. Kupfermann, R. S. Goldstein, and K. R. Weiss (1983) Lesion of a serotonergic modulatory neuron in Aplysia produces a specific defect in feeding behavior. Brain Res. 260: 151-155.

Sato, M., G. Austin, H. Yai, and J. Maruhashi (1968) The ionic permeability changes during acetylcholine-induced responses of Aplysia ganglion cells. J. Gen. Physiol. 51: 321-345.

Schwartz, J. H., A. Elste, E. Shapiro, and H. Gotoh (1986) Biochemical and morphological correlates of transmitter type in $\mathrm{C} 2$, an identified histaminergic neuron in Aplysia. J. Comp. Neurol. 245: 401-421.

Shapiro, E., V. F. Castellucci, and E. R. Kandcl (1980) Prcsynaptic inhibition in Aplysia involves a decrease in the $\mathrm{Ca}^{2+}$ current of the presynaptic neuron. Proc. Natl. Acad. Sci. USA 77: 1185-1189.

Shimahara, T., and B. Peretz (1978) Soma potential of an interneurone controls transmitter release in a monosynaptic pathway in Aplysia. Nature 273: 158-160.

Shimahara, T., and L. Tauc (1975) Multiple interneuronal afferents to the giant cells in Aplysia. J. Physiol. (Lond.) 247: 299-319.

Shuster, M. J., J. S. Camardo, S. A. Siegelbaum, and E. R. Kandel (1985) Cyclic AMP-dependent protein kinase closes the serotoninsensitive $\mathrm{K}^{+}$channels of $A$ plysia sensory neurones in cell-free membrane patches. Nature 313: 392-395.

Siegelbaum, S. A., J. S. Camardo, and E. R. Kandel (1982) Serotonin and cyclic AMP close single $\mathrm{K}^{+}$channels in Aplysia sensory neurones. Nature 299: 413-417.

Susswein, A. J., K. R. Weiss, and I. Kupfermann (1978) The effects of fond arousal on the latency of biting in Aplysia. J. Comp. Physiol. 123: 31-41.

Treistman, S. N., and P. F. Drake (1979) The effects of cyclic nucleotide agents on neurons in Aplysia. Brain Res. 168: 643-647.

Walsh, J. H., and J. H. Byrne (1985) Cyclic AMP and calcium sensitivity of the 5-HT response in tail sensory neurons of Aplysia. Soc. Neurosci. Abstr. 11: 789.

Weight, F. F. (1974) Physiological mechanisms of synaptic modula- 
tion. In The Neurosciences, Third Study Program, F. O. Schmitt and F. G. Worden, eds., pp. 929-941, M.I.T. Press, Cambridge, MA.

Weinreich, D. (1977) Synaptic responses mediated by identified histamine-containing neurones. Nature 267: 854-856.

Weinreich, D. (1978) Histamine-containing neurons in Aplysia. In Biochemistry of Characterised Neurons, N. N. Osborn, ed., pp. 153175 , Pergamon, Oxford, UK.

Weinreich, D., and Y. T. Yu (1977) The characterization of histidine decarboxylase and its distribution in nerves, ganglia and in single neuronal cell bodics from the CNS of Aplysia californica. J. Neurochem. 28: 361-369.

Weinreich, D., M. W. McCaman, R. E. McCaman, and J. E. Vaughn (1973) Chemical, enzymatic and ultrastructural characterization of 5-hydroxy-tryptamine-containing neurons from ganglia of Aplysia californica and Tritonia diomedia. J. Neurochem. 20:969-976.

Weinreich, D., C. Weiner, and R. McCaman (1975) Endogenous levels of histamine in single neurons isolated from the CNS of Aplysia californica. Brain Res. 84: 341-345.

Weiss, K. R., and I. Kupfermann (1976) Homology of the giant serotonergic neurons (metacerebral cells) in Aplysia and pulmonate molluscs. Brain Res. 117: 33-49.

Weiss, K. R., and I. Kupfermann (1977) Serotonergic neuronal activity and arousal of feeding in Aplysia californica. In Aspects of Behavioral Neurobiology, J. A. Ferrendelli, ed., pp. 66-89, Society of Neuroscience Symposium No. 3, Bethesda, MD.

Weiss, K. R., J. L. Cohen, and I. Kupfermann (1975) Potentiation of muscle contraction: A possible modulatory function of an identified serotonergic cell in Aplysia. Brain Res. 99: 381-386.

Weiss, K. R., J. L. Cohen, and I. Kupfermann (1978a) Modulatory control of buccal musculature by a serotonergic neuron (metacerebral cell) in Aplysia. J. Neurophysiol. 41: 181-203.

Weiss, K. R., E. Shapiro, J. Koester, and I. Kupfermann (1978b) A histaminergic synaptic potential produced by a voltage-dependen apparent decrease of conductance in the metacerebral cell of Aplysia. Soc. Neurosci. Abstr. 4: 210.

Weiss, K. R., D. E. Mandelbaum, M. Schonberg, and I. Kupfermann (1979) Modulation of buccal muscle contractility by serotonergic metacerebral cells in Aplysia: Evidence for a role of cyclic adenosine monophosphate. J. Neurophysiol. 42: 791-803.

Weiss, K. R., U. T. Koch, J. Koester, S. C. Rosen, and I. Kupfermann (1982) The role of arousal in modulating feeding behavior of Aplysia: Neural and behavioral studies. In The Neural Basis of Feeding and Reward, B. G. Hoebel and D. Novin, eds., pp. 25-57, Haer Institute, Brunswick, ME.

Weiss, K. R., H. J. Chiel, U. Koch, and I. Kupfermann (1986a) Activity of an identified histaminergic neuron, and its possible role in arousal of feeding behavior in semi-intact Aplysia. J. Neurosci. 6: 2403-2415.

Weiss, K. R., H. J. Chiel, and I. Kupfermann (1986b) Sensory function and gating of histaminergic neuron $\mathrm{C} 2$ in Aplysia. J. Neurosci. 6: 2416-2426. 